Pre-print for Charalabidis, Y. and Koussouris, S. (eds) Empowering Open and Collaborative Governance. Springer-Verlag, Germany. Pp181-198

\title{
Distributed discussion: an integrated eParticipation model for engaging young people in technology policy
}

\author{
Ella Taylor-Smith, Simone Kimpeler, Pille Pruulmann-Vengerfeldt \\ Edinburgh Napier University, 10 Colinton Road, Edinburgh, EH10 5DT, itc@napier.ac.uk \\ Fraunhofer Institute Systems and Innovation Research, Karlsruhe, Germany, \\ simone.kimpeler@isi.fraunhofer.de \\ University of Tartu, Ülikooli 18, 50090, Tartu. Estonia, pille.vengerfeldt@ut.ee
}

\begin{abstract}
This chapter describes an eParticipation model, designed to be especially appropriate to young people and complex topics: distributed discussion. It draws on the experiences of the HUWY project, which piloted a distributed discussion model, in four countries, to assess how this supported young people's engagement. The pilot revealed that young people valued structured and well supported discussions, particularly well-facilitated offline discussions. Integrating online and offline, national and international elements are the advantages and challenges of this model. This chapter aims to give an overview of the theoretical basis, process and impacts of the model and to provide recommendations for future development and use.
\end{abstract}

\section{Introduction}

HUWY (Hub Websites for Youth Participation) was an eParticipation Preparatory Action project, which piloted a distributed (networked) discussion. The pilot ran in Estonia, Germany, Republic of Ireland and the UK, from 2009 to 2011. HUWY aimed to find good ways to support young people to discuss Internet problems and improvements and to encourage policy-makers to interact with the resulting ideas. Young people in each country chose topics (e.g. Cyberbullying, Privacy) to focus the project, including an open thread about Internet experiences.

HUWY's eParticipation innovation is the method to bring people into policymaking: distributed discussion. Networked hub websites contain information about the project, well-structured background materials, the results of young peo- 
ple's discussions and feedback from policy-makers. There is one hub website for each pilot country, with localised information and language. Young people hold discussions in their own chosen settings: on websites (organisational or social) or in offline settings. Discussion groups post their results on their country's hub. The four country hubs are linked by an EU hub http://huwy.eu/: a global entry point and place to summarise results for EU policy-makers (Fig. 1).

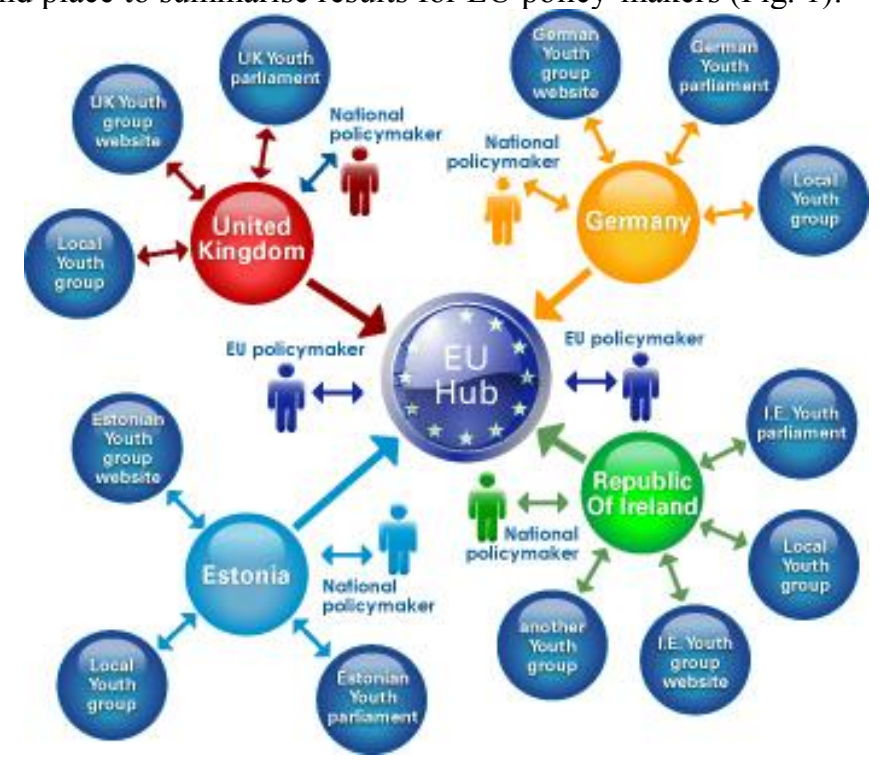

Fig. 1. HUWY Hub Structure

The distributed discussion model was devised to be as flexible and inclusive as possible: to enable young people to get involved in issues that were important to them, while they controlled the place and format of this involvement. It was designed to include youth groups who had their own online spaces, especially those already talking about HUWY topics, inspired by Steinberg and Mayo's (2007) suggestion that Government work with established online communities. It was also designed to include more casual groups, meeting on social networking pages or even offline.

The HUWY pilot included an extensive evaluation process, focused on impacts, sustainability, scalability, user engagement and the effects of involvement for young people. The evaluation was internal to the pilot, in terms of time (during the live pilot period) and personnel (conducted by the HUWY teams), but using inputs from external participants. The results reveal the strengths and weaknesses of the distributed discussion model, which this chapter aims to summarise, to provide relevant information to future users of distributed discussion models. 


\section{The theoretical and practical context}

\subsection{Combination of distributed and centralised actions}

The HUWY distributed discussion model supported a combination of national and transnational approaches, online and offline activities, to get young people engaged in Internet policy-making. The model promoted country-specific strategies to get policy-makers, youth organisations and young people involved. HUWY piloted a grassroots approach in which local discussions are, ideally, self-organised, but with strong context-sensitive support by regional project partners. So, a hub website was implemented in each of the four pilot countries, offering background information about the project and the topics, materials to support discussions, profiles of youth groups and policy-makers, posts of discussion results and feedback comments from policy-makers. The four hubs are networked via an EU-hub. The hubs are created from open source components. The HUWY project was not about developing new software but about using the Internet as it is, especially the social networks extensively used by young people in Europe. The HUWY consortium has taken up the challenges set by Coleman and Rowe (2006):

When seeking to engage with young people, decision makers should utilise those sites and methods of communication that young people already use, rather than simply building new websites and expecting young people to come to decision makers.

HUWY has been designed to support the use of whatever sites and software youth groups choose, as well as supporting groups who hold discussions offline. This is essential in countries like Ireland and the UK, where rural groups may have limited access to broadband. The hub structure is the key element of the dissemination strategy on a national level, while local actions support the involvement of (potential) participants in face-to-face settings, like workshops.

\subsection{Everyday political talk and inclusion}

It has long been suggested that democracy needs an overhaul and that alienation between state and subjects is a significant problem. Many authors (e.g. Dahlgren, 2006 and MPFS, 2010) suggest that technology is seen as a contribution to the solution; many attempts have been made to use online technologies in this way. Dahlgren sees online technologies as especially relevant: important in increasing access and availability, but also enabling filtering of everyday talk into political action. Everyday talk is where most people contribute to the public sphere (Kim 
and Kim, 2008). In this context, HUWY aimed to involve young people in discussions about Internet policy issues. Further, classic deliberation models may provide nicely formatted arguments for readers, but can dissuade people from joining in (Sanders, 1997). As Monnoyer-Smith and Wojcik (2011) point out, formal deliberation

can disqualify not only certain communities with oral traditions which are directed towards the expression of self, such as storytelling or the narration of personal histories; but also disqualify all those whose personal culture and education renders inapt for public expression and the presentation of a coherent, justified argument.

This is extremely relevant for young people, whose lack of confidence can be a barrier to their public participation, but who have valid contributions to make. HUWY believe that young people's extensive use of the Internet makes them valuable expert stakeholders in Internet policy topics, though their legal and technical knowledge may be limited. Inspired by Innes and Booher's (2003) powerful example of the Sacramento Water Forum, supported by their introduction to relevant dialogue theories, the HUWY project encouraged groups to use a variety of dialogic methods to explore and share both relevant personal experiences and information about the topics, provided by the partners on the hub websites.

\subsection{Young people and the Internet}

The HUWY project grew out of a wealth of research into eParticipation and the Internet and young people. In particular, HUWY is inspired by UK Children Go Online ${ }^{1}$ and its sister projects EU Kids Online $I$ and $I I^{2}$. While these studies are primarily concerned with children, and HUWY targets young adults (around 16 21), an observation from their research provided our inspiration:

The challenge is clear: how can society effectively facilitate the opportunities for children and young people online (i.e. positive regulation) while also reducing or managing the risks they encounter online (i.e. negative regulation)? There is a growing consensus that meeting this challenge is a task for multiple stakeholders, not simply a new burden for already over-taxed parents. For all concerned, this demands adapting to rapid change, learning new forms of expertise (including enabling and critical literacies), apportioning responsibility flexibly among relevant parties, identifying feasible strategies for enhancing safety, adapting local or national experience to confront a global phenomenon and, last, acknowledging some very real limits of regulatory power. (Livingstone, 2007)

The UK's Byron Review identifies both risks and advantages to young people in using the Internet (and video games) and, explicitly recognises the importance of young people's informed involvement in tackling these issues:

\footnotetext{
${ }^{1} \mathrm{http} / / /$ www.lse.ac.uk/collections/children-go-online/UKCGOfinalReport.pdf

${ }^{2}$ http://www2.1se.ac.uk/media@1se/research/EUKidsOnline/Home.aspx
} 
Children and young people need to be empowered to keep themselves safe - this isn't jus about a top-down approach. Children will be children - pushing boundaries and taking risks. At a public swimming pool we have gates, put up signs, have lifeguards and shallow ends, but we also teach children how to swim. (Byron, 2008)

HUWY encouraged young people to explore their own experience and the wider context, developing skills and informed opinions, before publishing their ideas on the hub websites for policy-makers to read: a more bottom-up approach. Topdown agendas lack convergence between those emphasising commercial expansion of the Internet (e.g. i2010 EU Policy Framework for the Information Society and $\mathrm{Media}^{3}$ ) and those which emphasise the protection of Internet users (e.g. the Safer Internet Program ${ }^{4}$ ). In many countries, these two objectives are the responsibilities of quite different government departments and conflicts arise over regulation. Policies which affect Internet use are developed at all government levels: local, regional, federal, national, EU and international. This tangled policy-making arena makes it difficult to identify organisations responsible for specific topics to influence policy directions. In the HUWY project, this led to challenges in providing information about which government departments were responsible, especially for larger countries with older legislatures: Governance structures in Germany and the UK are federalised and devolved, respectively. Departments and responsibilities change over time, but mismatches remain between the centuries of tradition and new, cross-government topics, like the information society. Whereas, Estonia is a small country with a new democracy, where many of the Internet regulations are newly developed, within the process of re-establishing the country. However, Estonia lacks a long-term tradition of engagement in policy making: Soviet history has forced Estonia to re-invent much of its civic society (Runnel, PruulmannVengerfeldt, and Reinsalu, 2009). Thus, in most countries, until the youth groups' results were posted, we could not be specific enough about the areas covered to identify the right policy organisation. It was also difficult to align young people's priorities with top-down engagement opportunities, like consultations.

\subsection{Science and technology policy}

Internet topics involve complex legal and technical factors, as well as touching on matters central to young people's lives. At the beginning of the pilot, we worked with young people to identify topics and discovered that they had a wealth of experience to share, but this was not always sufficiently grounded in knowledge, about technical or legal aspects, to support meaningful progress. We needed to both engage and inform, to spark and support discussions. The HUWY distributed discussion aimed to support informed discussion on Internet topics:

\footnotetext{
${ }^{3} \mathrm{http} / /$ ec.europa.eu/information_society/eeurope/i2010/index_en.htm

${ }^{4} \mathrm{http}$ ///ec.europa.eu/information_society/activities/sip/index_en.htm
} 
- through providing good quality background materials on the hubs;

- structuring this by topic and engagement level, to lead, through items that attract attention, to materials which support topic exploration and onto materials which support groups to work on their ideas to improve the Internet;

- providing information in various formats (e.g. text, video, podcast) and enabling young people to search by format;

- creating materials to support discussions, on or offline (e.g. for teachers, for peer facilitated groups, agendas and information sheets for download);

- localising information;

- supporting young people to create multimedia and post it on the hubs;

- hosting structured discussions at HUWY events and by visiting youth groups;

- encouraging young people to explore the topics in discussions with their peers.

We believe that this model will be useful to people using the Internet to support public engagement in policy discussions on topics, like nanotechnology, genomics and climate change. Like these issues, HUWY spans everyday experience with scientific, technical, legal and moral complexity. Legislation and political initiatives which affect the Internet need technological realism: while policies should not be led by technology fashions, they need to be reviewed by experts to highlight unintended loopholes or side effects. Equally, cultural impacts require consideration: the Internet is central to young people's work, studies, social and family life. Young people are a kind of local stakeholder, whose input is crucial:

We need to ensure that the correct value settings are in place so that the information society has a reasonable chance of running smoothly, of not crashing (Duff, 2008).

\section{Pilot objectives, requirements and implementation}

The objectives of the HUWY project grew out of the context described above, influenced by the goals and experience of the initiators and funders and grounded in current theory. The high level objectives of the project are to

- Increase involvement in democracy

- Involve young people in policy developments related to the Internet and its governance

- Advance eParticipation.

Fifteen objectives, derived from these, are the basis of requirements, implementation and evaluation (Table 1):

Table 1: HUWY Objectives

Increase Involvement in democracy

Objective 1 To increase young people's involvement in democracy through a positive experience 
that follows best practice established in eParticipation

Objective 2 To demonstrate that young people's views are sought and that their opinions are valued Objective 3 To contribute to the development of a European public sphere

Involve young people in policy developments related to the Internet and its governance

Objective 4 To involve young people in discussions on issues related to the Internet, its use and regulation

Objective 5 To support young people to become involved and gain understanding of relevant issues, through providing information in accessible formats and supporting their deliberation; and to provide a useful resource about Internet policy issues, in national and EU contexts

Objective 6 To map chosen areas of the topic agenda to policy and legislative responsibility (national / EU level) clarifying political structures relevant to the topic

Objective 7 To illustrate the role of national governments and parliaments, in designing and applying EU legislation, especially via the working relationships between EU and national bodies, as set out in the Treaty of Lisbon

Objective 8 To support young people to develop and follow best practice in using the Internet, thus contributing to their own safety, their peers' safety and increasing positive experiences of the Internet

\section{Advance eParticipation}

Objective 9 To trial an innovative model for distributed discussion

Objective 10 To provide a specific and transparent connection between young people and decision-making bodies

Objective 11 To increase young people's skills in using online tools for deliberation and eParticipation

Priorities of young people and policy-makers

Objective 12 Project evaluates well using young people's evaluation factors

Objective 13 Young people's preferred outcomes are met

Objective 14 Project evaluates well using policy-makers' evaluation factors

Objective 15 Policy-makers' preferred outcomes are met

The teams worked together with young people and policy-makers to implement the project, based on these objectives. Use-case scenarios were developed to clarify the envisaged use of the hub websites and associated offline processes. Workshops and focus groups with young people were held to choose the topics and identify the best ways to support the discussions and market the project to young people and youth groups. A list of topics was identified and prioritised (Table 2).

Table 2: Topics chosen for youth discussions in HUWY pilots

\begin{tabular}{|c|c|c|}
\hline Topics in UK and Ireland & Topics in Estonia & Topics in Germany \\
\hline Cyberbullying & Cyberbullying & Cyberbullying \\
\hline Child abuse & Child safety online & Censorship and freedom of opinion \\
\hline ID theft, privacy and phishing & $\begin{array}{l}\text { Safety online (related to ID } \\
\text { theft, shopping etc) }\end{array}$ & $\begin{array}{l}\text { Safety online (related to ID theft, } \\
\text { shopping etc) }\end{array}$ \\
\hline
\end{tabular}




\begin{tabular}{lll}
\hline File-sharing & Copyright & File-sharing \\
Open thread & Open thread & Open thread \\
Our experiences & Our experiences & Our experiences \\
\hline
\end{tabular}

As HUWY is an eParticipation pilot, investigating a networked discussion among young people, the hub websites are central to all activities. In each of the four EU pilot countries, HUWY hub websites were implemented, offering nationally contextualised information about the topics and the project, with structured space for discussion results, comments and policy-makers' feedback. Beta hubs were created on the WordPress Multi User platform, which turned out to be unable to support some more complex functionality. So, Gamma hub websites were created from Drupal components, towards the end of the pilot. These mirrored the structure and design of the Beta hubs, but used Drupal's community tools to better support groups to work online and publish their results.

While developing and implementing these hub websites, HUWY also implemented offline, face-to-face activities, right from the beginning of the project, to get the grass growing. The HUWY pilots involved over 50 events to bring young people, youth groups and policy-makers into the project and disseminate the results, including workshops, information events, visits to schools and youth groups and a transnational residential summer school, in July 2010. This youth exchange (http://eysm.eu/) was organised by HUWY partners and co-funded by Léargas, under the EU's Youth in Action Progamme. It brought together young people from HUWY pilot countries, in Ireland, to investigate HUWY topics and present ideas using multimedia. It was a valuable experience for participants and created lively media, which was posted on the hub websites and used in subsequent workshops. It was one of a very few transnational events for HUWY participants.

\section{User engagement assessment and sustainability review}

The HUWY assessment approach resembles current best practice in eParticipation evaluation (cf. Macintosh and Whyte, 2006 and Lippa et al, 2007) as it

- works with stakeholders to integrate their objectives;

- addresses objectives from social, technical and political perspectives;

- uses a triangulation of instruments to gather data, verify results and derive recommendations for future actions.

During the first phase of the evaluation, the HUWY team investigated the evaluation factors from a user perspective. This added specific detail to the objectives derived from the overall projects goals and helped to identify Key Evaluation Factors (KEF) within the user engagement assessment (Table 3). 
Table 3 Key Evaluation Factors

KEF1 To increase young people's involvement in democracy through a positive experience that follows best practice established in eParticipation.

KEF2 To demonstrate that young people's views are sought and that their opinions are valued.

KEF3 To involve young people in discussions on issues related to the Internet, its use and regulation. Also includes the number and variety of groups of young people that are involved in the project.

KEF4 To support young people to develop and follow best practice in using the Internet, thus contributing to their own safety, their peers' safety and increasing positive experiences of the Internet.

KEF5 To contribute to the development of a European public sphere.

KEF6 The amount of ideas that will be taken into account in the policy making process.

KEF7 To trial an innovative model for distributed discussion.

The user engagement assessment focused on two groups of participants: young people and policy-makers. Each team used the same diverse set of methods to gather comparable data, during the same time period. Instruments used:

- Web statistics, using Google Analytics;

- Survey instruments, online survey $(n=48)$;

- Semi-structured interviews with young people $(n=21)$, teachers and youth workers $(n=2)$ and policy-makers $(n=3)$

- Text analysis of posts to evaluate the quality of discussions ( $\mathrm{n}=116$ posts) and to give an overview of the proposed policy measures;

- Quantitative data about discussions in all four countries;

- Reports from workshops and events (50+ workshops);

- Model elements check (milestones checklist);

- Success factors templates, completed by HUWY teams;

- Usability tests were conducted in two countries, accessibility testing in one.

The technology implemented was also reviewed in terms of usability, sustainability and scalability. This included technical assessments of the implementation of both Beta and Gamma hubs. The sustainability and scalability review identified strengths, weaknesses and recommendations for anyone intending to implement a similar initiative. The review also used the experience of the HUWY teams and input from external interested parties to identify future uses of the HUWY model ${ }^{5}$.

\section{Impact Assessment}

\footnotetext{
${ }^{5}$ Full reports available here: http://www.iidi.napier.ac.uk/c/publications/grantid/13363192
} 


\subsection{Methodology}

The impact assessment is a project internal analysis of how and to what extent the objectives and expected impact have been met through different actions. Besides the normative approach of assessing intended impacts, the combination of diverse methods like stakeholder surveys and content analyses in this approach, also help to gather information about the actual outcomes of the project, which may not be intended effects and may be positive or negative.

The output and impacts of the HUWY project were assessed by a meta-analysis of the user engagement and sustainability evaluation results, using an impact logic schema (Table 4). This shows the ideal relation of each input to its expected key output, direct and indirect outcomes and impacts. The chart serves as a model: the project team is aware that there are no simple causal effects from input to impact. The aim was to identify how the tasks, developed out of the objectives, and the actions which were carried out, were in line with actual final impacts.

Table 4: Impact Logic Chart for HUWY trial

\begin{tabular}{|c|c|c|c|}
\hline Input & Output & Outcome & Impact \\
\hline Topic selection & $\begin{array}{l}\text { Youth-specific in- } \\
\text { formed content }\end{array}$ & Reliable information & $\begin{array}{l}\text { More deliberated opin- } \\
\text { ions }\end{array}$ \\
\hline $\begin{array}{l}\text { National hubs as I\&C } \\
\text { platform }\end{array}$ & Multimedia content & Better understanding & Advanced e-skills \\
\hline \multirow{2}{*}{$\begin{array}{l}\text { Facilitators recruitment } \\
\text { / training }\end{array}$} & $\begin{array}{l}\text { Online and offline dis- } \\
\text { cussions }\end{array}$ & Bottom-up discussions & $\begin{array}{l}\text { Advancing } \\
\text { eParticipation }\end{array}$ \\
\hline & $\begin{array}{l}\text { Results of discussions } \\
\text { documented }\end{array}$ & $\begin{array}{l}\text { Public discourse about } \\
\text { Internet governance }\end{array}$ & $\begin{array}{l}\text { Youth contributions are } \\
\text { sought }\end{array}$ \\
\hline $\begin{array}{l}\text { Policy-makers' recruit- } \\
\text { ment }\end{array}$ & Policy-makers' profiles & $\begin{array}{l}\text { Policy-makers com- } \\
\text { menting }\end{array}$ & Effects on policy \\
\hline User involvement & $\begin{array}{l}\text { Comments and content } \\
\text { posted }\end{array}$ & User-generated content & $\begin{array}{l}\text { Increased involvement } \\
\text { in democracy }\end{array}$ \\
\hline Dissemination & Use of social software & Different channels & Scalability \\
\hline
\end{tabular}

\subsection{HUWY Inputs}

Based on the project objectives, six key tasks were defined at the input-side:

- Topic selection: make sure that discussion topics are relevant to young people.

- National hubs as information and communication platforms: to support both national/regional contexts and European cross-links. 
- Recruitment and training of facilitators: to get young people engaged and to provide guidance and structure for discussion processes.

- Recruitment of policy-makers: to get policy-makers involved, to take young people's ideas into regulatory bodies; also important in motivating engagement.

- User involvement: engagement in a process of dialogue with peers, to explore the topics and possible solutions; to produce content and post their results.

- Dissemination: creating content and actions, including use of social networks.

These tasks require a series of diverse, but interconnected online and offline actions, events and skills and took a lot of time. HUWY teams in each country became responsible for: working with young people to choose the topics; specifying how the pilot should be implemented; providing good quality information, in various formats, on each HUWY topic; updating the hubs, through a content management system; (in Germany and Estonia) providing translations for Beta and Gamma hubs; promoting HUWY to young people and youth groups; recruiting, training and supporting facilitators; helping facilitators post results online; promoting results to policy-makers and encouraging them to post feedback. Teams then implemented the evaluation processes and impact assessment.

The project was designed to support the use of whatever sites and software for online communication youth groups chose. Despite the openness of the idea, the project needed the hub websites as central nodes, so technical weaknesses caused significant problems. The relationship between online and offline activities, between established sites and new content, needs a central, easy to use, online home.

\subsection{HUWY Outputs}

The user engagement assessment indicated that the distributed discussion model was successfully implemented in the HUWY pilot, although some challenges were identified in terms of the engagement of youth groups (depth and quantity), holding online discussions, and active involvement of policy-makers. The following sections assess success in meeting output goals, based on data gathered through the evaluation instruments (Section 4) and following the schema in Table 4.

HUWY managed to address the issue of youth specific informed content as the analysis of the youth groups' results posts, in combination with user survey results, reveal that the content provided was of interest to the participants and useful in their discussions. HUWY teams provided background multimedia content, searchable by format. Content accessed was rated well, but few discussion groups generated their own multimedia.

Both online and offline discussions were encouraged and supported, but most groups favoured face-to-face environments. We considered policy-makers' profiles to be an important signal that HUWY was of interest to relevant people in power, but few policy-makers provided information, for their profiles, which illus- 
trated their potential influence and only $10 \%$ of posts received policy-makers' feedback. At events, policy-makers mostly responded well to young people's ideas and young people really valued this.

In terms of comments and content posted the challenge was to persuade people to start discussion groups, keep discussions going and to get results posted. Guidelines for the organisation, facilitation and documentation of the discussions, as well as lesson/activity plans, topic guides and templates for results were provided. HUWY also aimed to integrate social software tools for recruitment, discussions and dissemination, but hub downtime caused problems.

\subsection{HUWY Outcomes}

The evaluation of user engagement in the HUWY project leads to the following conclusions, based on the Key Evaluation Factors:

- HUWY has increased young people's involvement in democracy and has provided positive experiences for participants. EParticipation elements were less successfully realised (KEF 1).

- Policy-maker involvement was only partially fulfilled. However, the project confirms the importance and relevance of involving policy-makers in eParticipation projects and emphasises the rewards of bringing young people and policy-makers together at events (KEF 2).

- Once involved, the different young people and their groups provided topical, considered and relevant input about the Internet, its use and regulations. However, the numbers of participants was low in most countries (KEF3).

- The project has supported young people's skills in deliberation and better understanding of group processes and, through this, to a small extent, supported the development of the EU public sphere (KEF 4 and KEF5).

- There is no evidence of young people's ideas being taken into account in the policy-making process at this stage (KEF 6).

- The distributed discussion model is relevant and provides valued opportunities to support young people's informed participation. All feedback mechanisms show that the offline discussions and events were vital components of the model and should be included in any distributed discussion (KEF 7).

The following describes the outcomes using the Impact Logic Chart schema.

All project partners prioritised reliable information in the format of background materials on the hubs, e.g. naming the authors of articles, providing pro and contra arguments where possible, indicating sources of information and links to further reading and other websites. Information on the websites, and at discussions, supported a better understanding of complex topics. Estonian partners commissioned materials specifically to be used by high school teachers in discus- 
sions on HUWY topics. Young people also gained insight into different views and perspectives through discussion activities. In Germany, some discussion groups held scenario workshops to develop joint perspectives. Others used role play: taking different roles (e.g. teachers, parents, police) to explore and understand points of view.

Facilitators were central to HUWY as one of the aims was to support bottomup discussions, ideally using peer facilitation. Their role was organising groups and managing group discussions and results posted on the hubs as well as liaising with the HUWY team. (Some facilitators received well-deserved payment.)

Very few policy-makers commented on youth group results posts. Estonians were more successful in engaging policy-makers. Germany had problems in motivating them, possibly due to the Internet Governance topics, as discussed in section 2.3 above. In Ireland and the UK, changes and crises in government caused particular problems within the pilot period.

As an outcome, user-generated content was published, despite most groups holding discussions offline. Results were posted on the hubs and some groups created multimedia content and uploaded it (e.g. http://huwy.eu/de/node/429). Aiming to use different channels, HUWY teams used Facebook, Twitter and other social networks. A few participants used their Facebook profiles to link to HUWY and to comment on results. But no real discussions took place on social networking sites.

\subsection{HUWY Impacts}

We will again follow the Impact Logic Chart (Table 4) to discuss each of the outlined impacts. We use "deliberated opinions" to describe interactions within the discussion groups, rather than to refer to classic deliberation methods, which could exclude a dialogic approach. The evaluation showed that the distributed discussion format, used in HUWY, led young people to explore topics and form ideas. The facilitators were trained to support deliberative thinking, listening to others and to manage their groups. Many participants developed a more critical attitude towards the use of certain Internet applications.

Young people were able to advance their e-skills through learning about the Internet in theory through the discussion of experiences, information provided, challenges and possible solutions. They were also encouraged to practice eParticipation and digital literacy skills: searching for information, learning about topics and tasks of policy-makers, creating results posts and commenting on other posts. The research team has been able to advance eParticipation through piloting the distributed discussion with extensive evaluation and analysis of results ${ }^{6}$.

${ }^{6}$ Full reports available here: http://www.iidi.napier.ac.uk/c/publications/grantid/13363192 
The recruitment of policy-makers was disappointing in all countries, which made it difficult to assess the model's support for the hubs as a place where young people could interact with policy-makers. HUWY did not demonstrate policy-makers seeking youth contributions. The volume of feedback posted was low and none implied measurable influence. HUWY is unlikely to have much impact on policy.

A qualitative increase in involvement in democracy, in terms of engagement and interest in democratic processes was observed at the individual level. However, participation was low: out of the four countries, only Estonia met their target number of participants. Due to low participation, the scalability of the model was not really tested. Social networking tools did not help HUWY to increase in scale, but this may be due to technical problems with the hubs as communication nodes.

\section{Conclusions and discussion}

The pilots validated the distributed discussion model as an effective way to involve young people by increasing the depth and quality of their ideas to improve the Internet. Participants had an enjoyable and rewarding experience that furthered their engagement with democracy and their awareness of best practice in using the Internet. The model's flexibility enabled a variety of people to become involved, without specialist deliberative or technical skills, or even good Internet access.

The pilots also revealed the challenges of the model. It is resource-intensive, requiring teams to undertake a wide variety of tasks, during all pilot phases from planning to evaluation and dissemination. Young people were reluctant to take on the roles that we hoped they would enjoy, such as organising their own discussions (on or offline) and bringing peers into the project through social networks. Those who did take on these roles provided an impressive list of positive personal outcomes in evaluation interviews. We suggest that these challenges can be met through funded partnerships with youth organisations. In particular, facilitators need to be rewarded for their hard work. In our experience, the skilled work undertaken by engagement workers is rarely described in detail, in either research reports or funding applications. Escobar (2011) describes engagement workers undertaking similar tasks to the HUWY teams: advocating the engagement process, organising, facilitating, mediating, translating, writing up, liaising and building relationships. Engagement workers "translate" between legal or policy documents and the materials they use with participants. HUWY teams created accessible summaries of legal positions for the hub websites. Engagement workers then translate the results of engagement exercises back into a form that is suitable for their employers. Perhaps, something similar in HUWY would have increased policy-maker feedback. Technology may extend the reach and impact of engagement, but there is little evidence that computer algorithms will be able to replace 
the full skill-set of engagement workers in the near future. People are needed to feed the grassroots, both on and offline.

Website implementation problems were a weakness at the heart of the pilots. Unlike Coleman and Rowe's model, HUWY is not initiated by decision-makers and needs its own online homes to link young people and policy-makers. Open source components can be the basis, but must be chosen carefully to reliably support all the functions necessary, in various languages. Our experience suggests that, although offline events were highly valued by our participants, the central hubs need to be implemented and integrated with social networks. We came to see social networking and offline discussions as an essential component of the model, to be integrated into the planning.

Social network applications, like Facebook, are currently, and increasingly, very popular means of communication, especially for young people (Eimeren and Frees, 2010 and MPFS, 2010), inspiring projects to support social media use in initiatives aiming to reach this target group. Williamson (2011) provides a helpful description of social media's current status and potential for civic participation:

Social media - the social web - is at the heart of a changing political and civic landscape, bringing together otherwise disparate individuals around shared beliefs. Weak ties - these networks of association - become precursors to civic engagement bridging multiple collections of acquaintances. Yet effective engagement is difficult to sustain. It is a manystage, cyclical and self-re-enforcing process and in this lies its weakness; faults in the process create numerous points of failure and so Web2.0 is a timely tool to support radical new ways of socially organising for effective change.

The hub website model is designed to support the integration of social networking tools, but in our case young people did not favour social networking sites, like Facebook, as forums for discussion. However, there is more potential to use social media to bring people into the project, to create more active links between participant groups and disseminate young people's results. These possibilities are discussed in more detail by Taylor-Smith and Lindner $(2009,2010)$.

HUWY is not the first initiative to integrate online and offline engagement settings. IDEAL-EU, another eParticipation Preparatory Action pilot, aimed to involve young people in discussions about climate change. It included online discussion forums, followed by an electronic town meeting, held in three EU cities at once, in November 2008. The town meeting involved keypad voting and face-toface discussions in small groups (Talpin and Wojcik, 2010). The method was inspired by America Speaks $21^{\text {st }}$ Century Town Meeting ${ }^{7}$ and other EU precedents. Talpin and Wojcik found

The subjective learning effect of deliberation appears to be stronger face-to-face than online, despite the higher informational content of IDEAL-EU online discussions. We investigated the potential origins of this rather paradoxical result, and argue that the emotional nature of face-to-face discussions could foster knowledge assimilation.

\footnotetext{
${ }^{7}$ http://americaspeaks.org/
} 
Monnoyer-Smith and Wojcik's (2011) comparison of online and offline debates, found that online debates supported both more formal deliberation characteristics, more diverse forms of expression and, in this case, enabled a wider variety of people to get involved. However, offline methods supported richer, livelier exchanges. Thus it seems that initiatives which combine both elements, like HUWY, could benefit from the best of both worlds. Hale (2011) describes the English National Health Service (NHS) using similar diverse resources for their "listening exercise" into plans to reform NHS, collecting thousands of inputs.

The next iteration of the distributed discussion should include offline events, at regular stages throughout the pilot. These should be well integrated with online elements: promoted on the hubs, using hub information resources. Offline events should create outputs which are posted on the hubs: video recordings, podcasts, text summaries and testaments from participants. These outputs become inputs into discussions, on and offline. Working in partnership with organisations which already support offline engagement could offset the additional resource use. Transnational distributed discussions should include transnational events.

The HUWY pilots provide a wealth of ideas and insights into methods to engage young people in debates about Internet policies. We hope these conclusions will be useful to people organising similar initiatives on complex topics of day to day importance to participants of all ages, but especially young people.

\section{Acknowledgements}

HUWY was co-funded by the European Commission and the project partners, under the eParticipation Preparatory Action. http://ec.europa.eu/information_society/activities/egovernment/policy/eparticipati on/index_en.htm

The involvement of the Estonian partners was supported by Estonian Target Financing measure SF0180017s07 "Estonia as an Emerging Information and Consumer Society: Social Sustainability and Quality of Life".

\section{References}

Byron, T (2008) Safer Children in a Digital World: Executive Summary. Department for Children, Schools and Family, and the Department for Culture, Media and Sport, London, UK.

Coleman, S and Rowe, C (2006) Remixing Citizenship Democracy and young people's use of the Internet; Carnegie Trust, UK

Dahlgren, P (2006) Civic participation and practices: Beyond 'deliberative democracy'. In: Carpentier, $\mathrm{N}$ et al (Eds) Researching media, democracy and participation: The intellectual 
work of the European Media and Communication Doctoral Summer School, University of Tartu Press, Tartu, 23-34.

Duff, A (2008). The Normative Crisis of the Information Society. Cyberpsychology: Journal of Psychosocial Research on Cyberspace, 2(1), article 1.

Eimeren B van and Frees B (2010) Fast 50 Millionen Deutsche Online - Multimedia für alle? (Ergebnisse der ARD/ZDF-Onlinestudie 2010). In Media Perspektiven. 2010 (7-8), pp334349.

Escobar, O (2011) The work of participation: local deliberative policy making as mediated by public engagement practitioners, 61st Conference of the Political Studies Association, April 2011, London

Hale, S (2011) The mechanics of listening. http://hale.dh.gov.uk/2011/05/25/the-mechanics-oflistening/. Accessed $30^{\text {th }}$ June 2011

Innes, J \& Booher, D (2003) Collaborative policymaking: governance through dialogue, in Hajer, M (Ed.) Deliberative policy analysis: understanding governance in the network society, New York: Cambridge University Press.

Lippa B, Aichholzer G, Allhutter D, Freschi AC, Macintosh, A and Westholm, H (2007) Demonet: D 13.3 DEMO-net booklet "eParticipation Evaluation and Impact". http://ics.leeds.ac.uk/Research/CdC/CdC\%20Publications/DEMOnet_booklet_13.3_eParticip ation_evaluation.pdf. Accessed $30^{\text {th }}$ June 2011

Livingstone, S (2007) Mapping the possibilities for beneficial online resources for children: issues of trust, risk and media literacy. Working paper for the EU Media Expert Seminar: More trust in contents - the potential of co- and self-regulation in digital media European Union

Kim, J and Kim, EJ (2008) Theorizing dialogic deliberation: everyday political talk as communicative action and dialogue, in: Communication Theory, 18, pp.51-70.

Macintosh, A and Whyte, A (2006); Evaluating how eParticipation changes local democracy. In Irani, Z and Ghoneim, A (eds) Proceedings of the eGovernment Workshop 2006, eGov06, London: Brunel University. ISBN: 1-902316-47-9

Mayo, E and Steinberg, T (2007) The Power of Information; OPSI, Norwich, UK

Monnoyer-Smith, L and Wojcik, S (2011) Technology and the Quality of Public Deliberation. A Comparison Between On and Off-line Participation; 61st Conference of the International Communication Association, Boston: United States, p5

Medienpädagogischer Forschungsverbund Sudwest (MPFS) (Ed.) (2010) JIM 2010 - Jugend, Information, (Multi-) Media. Basisstudie zum Medienumgang 12- bis 19-Jähriger in Deutschland. Stuttgart. http://www.mpfs.de/fileadmin/JIM-pdf10/JIM2010.pdf. Accessed $30^{\text {th }}$ June 2011

Runnel, P, Pruulmann-Vengerfeldt, P and Reinsalu, K (2009) The Estonian Tiger Leap from Post-Communism to the Information Society: From Policy to Practices. Journal of Baltic Studies, 40(1), 29 - 51.

Sanders, L. M (1997) Against Deliberation. Political theory 25(3), 347-376.

Talpin, J and Wojcik, S (2010) Deliberating Environmental Policy Issues: Comparing the Learning Potential of Online and Face-To-Face Discussions on Climate Change, in Policy \& Internet: Vol. 2 : Iss. 2 , Article 4.

Taylor-Smith, E and Lindner, R (2009) Using Social Networking Tools to Promote eParticipation Initiatives in Prosser, A and Parycek, P (eds) Proceedings of EDEM 2009 Conference on Electronic Democracy, September 7-8, 2009, Vienna; pp115 -121

Taylor-Smith, E and Lindner, R (2010) Social networking tools supporting constructive involvement throughout the policy-cycle in Parycek, $\mathrm{P}$ and Prosser, A (eds) Proceedings of EDEM 2010 - Conference on Electronic Democracy, May 7-8, 2010, Danube-University Krems, Austria; pp331-339

Williamson, A (2011) Driving CIVIC Participation Through Social Media in European Workshop at Perspectives of Web 2.0 for Citizenship Education in Europe, 7 - 9 April 2011, Brno, Czech Republic. http://www.bpb.de/files/KKY9CZ.pdf. Accessed 30 ${ }^{\text {th }}$ June 2011 